WHAT'S IN A STEAK?

A CROSS-CULTURAL STUDY ON THE QUALITY PERCEPTION OF BEEF

Working paper no. 39

June 1996 


\section{WHAT'S IN A STEAK? \\ A CROSS-CULTURAL STUDY ON THE QUALITY PERCEPTION OF BEEF}

Klaus G. Grunert

The Aarhus School of Business 


\section{EXECUTIVE SUMMARY}

1. With the Total Food Quality Model as point of departure, a study is described which analyses how consumers evaluate the quality of beef in a purchase situation in four European countries: France, Germany, Spain, and the United Kingdom. The study consisted of a series of focus groups and of an extended form of conjoint analysis which enables an estimatation of means-end structures.

2. Tradition and security, variation, atmosphere and social life, health, acceptance from family/children/guests, nutrition, demonstration of cooking abilities, and status are the most important purchasing motives in all four countries.

3. The most important quality aspects of beef are that it tastes good, is tender, juicy, fresh, lean, healthy and nutritious.

4. Purchasing motives as well as quality aspects are uni-dimensional in Germany, Spain, and the UK, while they are multi-dimensional in France. This implies that French consumers have a more sophisticated purchasing behaviour than consumers in the other countries.

5. Place of purchase and quality perception are related in all four countries, ie the butcher is regarded as a sort of guarantor of high quality. This applies less in the UK than in the other countries, however.

6. The most important concrete product characteristics, which consumers base their quality evaluation on, are fat content and colour. Fat is generally negative, and this applies to all aspects of fat. The positive effects of fat on taste and tenderness are unimportant. German consumers prefer dark meat, whereas Spanish consumers tend to prefer light meat.

7. I nformation about country of origin and breeding and feeding has no effect on quality perception.

8. The results suggest that producers of superior beef have a problem in communicating this quality to consumers, and that a quality grading system developed in co-operation between producer and retailer may be the best way to overcome consumer uncertainty in evaluating the quality of beef. 
A means-end approach to the quality perception of meat 1

Extending conjoint analysis 5

Design of study and data collection 8

Design of stimulus material and dependent variables 8

Quality cues $\quad 8$

Quality aspects $\quad 9$

Purchase motives 9

Selection of respondents and data collection $\quad 10$

$\begin{array}{ll}\text { Results } & 10\end{array}$

Dimensionality of quality aspects and purchase motives 10

Model estimation $\quad 12$

$\begin{array}{ll}\text { Strategy of analysis } & 12\end{array}$

Results for model A $\quad 15$

Results for model B $\quad 19$

Results for model C $\quad 21$

The cross-cultural core model $\quad 25$

Discussion and conclusions 26

$\begin{array}{ll}\text { References } & 29\end{array}$ 


\section{A MEANS-END APPROACH TO THE QUALITY PERCEPTION OF MEAT}

Consumers' evaluation of food quality is one of the more problematic areas in the study of consumer behaviour. Food comes in infinite variety, and food choices are a major component of all purchase decisions made by consumers. Food products are described by a large number of characteristics, but the degree of satisfaction obtained from consuming the product is often only loosely related to the cues available in the purchase situation. The reason is that the evaluation of central quality aspects, such as taste, presupposes the destruction of the product, because many times the product is not consumed as such but is further processed by cooking and combining several products into meals, and because many food products, like meat, are predominantly sold unbranded, removing a major quality cue which consumers otherwise can rely on.

Within the behaviourally-oriented analysis of consumer food choice, several broad approaches can be distinguished. The economics of information approach, the multi-attribute approach, hierarchical approaches, and integrative approaches will be mentioned.

Within the economics of information approach Nelson $(1970,1974)$ contributed the distinction between search goods, where the quality can be evaluated before the purchase, and experience goods, where the quality can be evaluated only after the purchase. In the latter case, consumers will try to infer the quality from surrogate indicators like a brand name with an established record of credibility or the market share of the product. Nelson's argument was later extended in two ways. Firstly, it was pointed out that most goods have aspects of both search and experience goods, and that it makes more sense to apply a multidimensional notion of quality which includes both search and experience characteristics (Wilde, 1980). For a food product, taste is a typical experience characteristic (unless tasting is allowed before the purchase), whereas fat content of a piece of meat is a search characteristic. Secondly, it was pointed out that there may be a third group of characteristics where the consumer never, not even after the purchase, has the possibility of detecting whether the product actually possesses the characteristic. Whether a vegetable has been ecologically produced, or whether a piece of meat was produced with due respect for animal welfare, are product characteristics which are not reflected in objective characteristics of the final product. These may be either impossible to verify due to a lack of tracing possibilities or may be verifiable only at prohibitive costs for the consumer (Andersen, 1994). These characteristics have been termed credence characteristics, because they are a question of the seller's credibility vis-à-vis the buyer (Andersen, 1994; Darby \& Karni, 1973). The economics of information approach does not provide a model of the qual ity perception process as such, since the questions of how consumers infer beliefs about experience and credence characteristics, and how they integrate such beliefs into an overall quality evaluation, are not treated explicitly.

Similar to the economics of information approach, multi-attribute approaches share the assumption that quality is a multidimensional phenomenon. Also here, overall quality is described by a set of characteristics (attributes). However, these need not be objective characteristics, but they are attributes perceived by the buyer. The buyer then forms an overall, one-dimensional quality evaluation by weighing the various attributes. This can take on several forms; in the simplest form, the degree to which a product is believed to possess an 
attribute is weighted against the subjective importance of that attribute. Many variations of this basic model have been used in consumer behaviour theory, the Fishbein attitude model (Fishbein \& Ajzen, 1975) being the most popular one. To some extent, the distinction between search, experience and credence characteristics has been incorporated into multi-attribute models by the distinction of intrinsic and extrinsic product attributes (Olson \& J acoby, 1972). Intrinsic attributes refer to attributes of the physical product, whereas extrinsic attributes refer to everything else. Extrinsic attributes, which include things like brand name, price, and sales outlet, are expected to be used mainly in the situations where information about intrinsic attributes is difficult to obtain, ie, in those choice situations which are characterised by a predominance of experience and/or credence characteristics.

Multi-attribute models have been the most widely used approach to analyse quality judgements in consumer behaviour, but they have also been widely criticised (eg, Grunert, 1989). One point of criticism is that the interrelationship of attributes is not taken into account: consumers may infer taste from price or healthiness from fat content; all of these are treated as attributes at the same level by multi-attribute models. This criticism is dealt with in a group of models we may call hierarchical models. They have in common the notion that consumers infer some attribute from others. These may be attributes at the same level of abstraction, as when al cohol content of a beer is inferred from the shape of the bottle, but in most cases the inference will be from the concrete to the abstract, as when taste of the beer is inferred from al cohol content and shape of the bottle (Cox, 1967; Geistfeld, Sproles \& Badenhop, 1977; Grunert, 1986).

The idea of inferring more abstract descriptors from concrete product attributes is central in means-end chain theory (Gutman, 1982, 1991; Olson, 1989; Olson \& Reynolds, 1983; Zeithaml, 1988). A means-end chain is a model of consumers' cognitive structures depicting how concrete product characteristics are linked to selfrelevant consequences. More specifically, it shows how a product characteristic (concrete or abstract) is linked to consequences (functional or psychosocial) of consumption, which in turn may be linked to the attainment of life values (instrumental or terminal). As an example, the concrete product characteristic low fat is linked to the abstract product characteristics fewer calories, linked to the consequences slimming (functional) and social acceptance (psychosocial), which leads to the values self-confidence (instrumental) and sel f-esteem (terminal). The major deficiency of these approaches is that, while the process of attribute inferral is adequately modelled, the final quality evaluation often remains foggy.

A few attempts have been made to integrate these various approaches into a unified framework for analysing the quality perception process for food products, the most notable cases being the work by Steenkamp (1989) and Andersen (1994). Both models assume that the qualities a consumer seeks in a food product are al ways experience and credence qualities. Search characteristics are used by the consumer only as indicators for the qualities actually sought, and these indicators cover both attributes of the product itself and other (eg, firm-specific) attributes. Based on these observable indicators, the consumer forms expectations about experience and credence qualities, which in turn are aggregated into an overall expected one-dimensional quality. The expected quality may then later be compared to the experienced quality, which will give rise to adjustments in the way future quality evaluations may be made. Grunert, Hartvig Larsen, Madsen and Baadsgaard (1996) have elaborated these approaches and devel oped 
the Total Food Quality Model, depicted in figure 1. One additional aspect in their model refers to the determinants of experienced as opposed to expected quality. The product characteristics the consumer uses as quality indicators in order to infer expected quality may also impact experienced quality, and not necessarily in the way the consumer expects. In addition, experienced quality will be influenced by product characteristics not used by the consumer in his/her quality evaluation process, and by the way the product is used in a meal preparation process. Related to this, a second additional aspect refers to the technical product specifications which will determine both the intrinsic quality cues that the consumer can perceive and the quality finally experienced. A third additional aspect refers to the sensory characteristics of the product, which Grunert et al. regard as important mediators between technical product specifications, meal preparation, and experienced quality. Fourthly, the consumer's expected quality evaluation as such, while important, will determine the consumer's intention to buy only in relation to the perceived costs associated with the product, where costs can be both monetary and other costs. Price can be both a cost cue and an extrinsic quality cue. Finally, they go beyond quality and look at consumer's purchase motives, extending the means-end chain line of thinking.

Regarding consumers' quality perception of meat in general and beef in particular, the intricacy of the relationships between quality cues and higher-order quality aspects has been known for a long time. Summarising much of the earlier literature in English on consumer preferences for beef, Barton (1970) condudes that consumers cannot relate visual and eating characteristics of beef reliably; according to Barton, consumers look for tenderness, juiciness and flavour and associate this with fresh appearance, maximum lean, absence of gristle, and a bright red colour. But even though this notion, which fits well with the core of the Total Food Quality Model, has been around for a long time, little research has explicitly addressed the issue. Much research on beef quality in food science has dealt with the relationships between technical product specifications and sensory characteristics as evaluated by a panel of trained tasters (see Dransfield et al., 1984, for a major study of this nature), which is useful for quality control purposes but says little about consumer quality perception. Other studies have addressed the impact of both extrinsic and intrinsic quality cues on sensory evaluation by 'real' consumers (eg, Godt et al., 1996; Oude Ophuis, 1994), ie, have related qual ity cues directly to aspects of experienced quality, but not looking at the process of how expected quality is formed in a purchase situation. Quite a number of studies have employed the Theory of Reasoned Action, a variant of the multi-attribute approach, to explain the frequency of buying beef or meat as compared to other food products (Richardson, Shepherd \& Elliman, 1993; Sapp, 1991; Shepherd \& Stockley, 1985; Shepherd \& Towler, 1992). While this gives some indication on what contributes to consumers' quality evaluation of meat as compared to other food, it does not explain how consumers discriminate within this product category. Also, while the Theory of Reasoned Action is not a hierarchical model and all beliefs explaining the attitude component are assumed to be at the same level of abstraction, the beliefs used in these studies sometimes do reflect different levels of abstraction (eg, Shepherd and Towler, 1992, used the set of beliefs healthy, fat, taste, expense, proteins, vitamins). Other studies have measured consumers' self-reported reasons for selecting pieces of meat (Maguire, 1994; Woodward, 1988), but confounded quality or cost cues which are visible at the time of purchase (eg, price, colour) with quality aspects which are part of expected and/or experienced quality (eg, taste). 


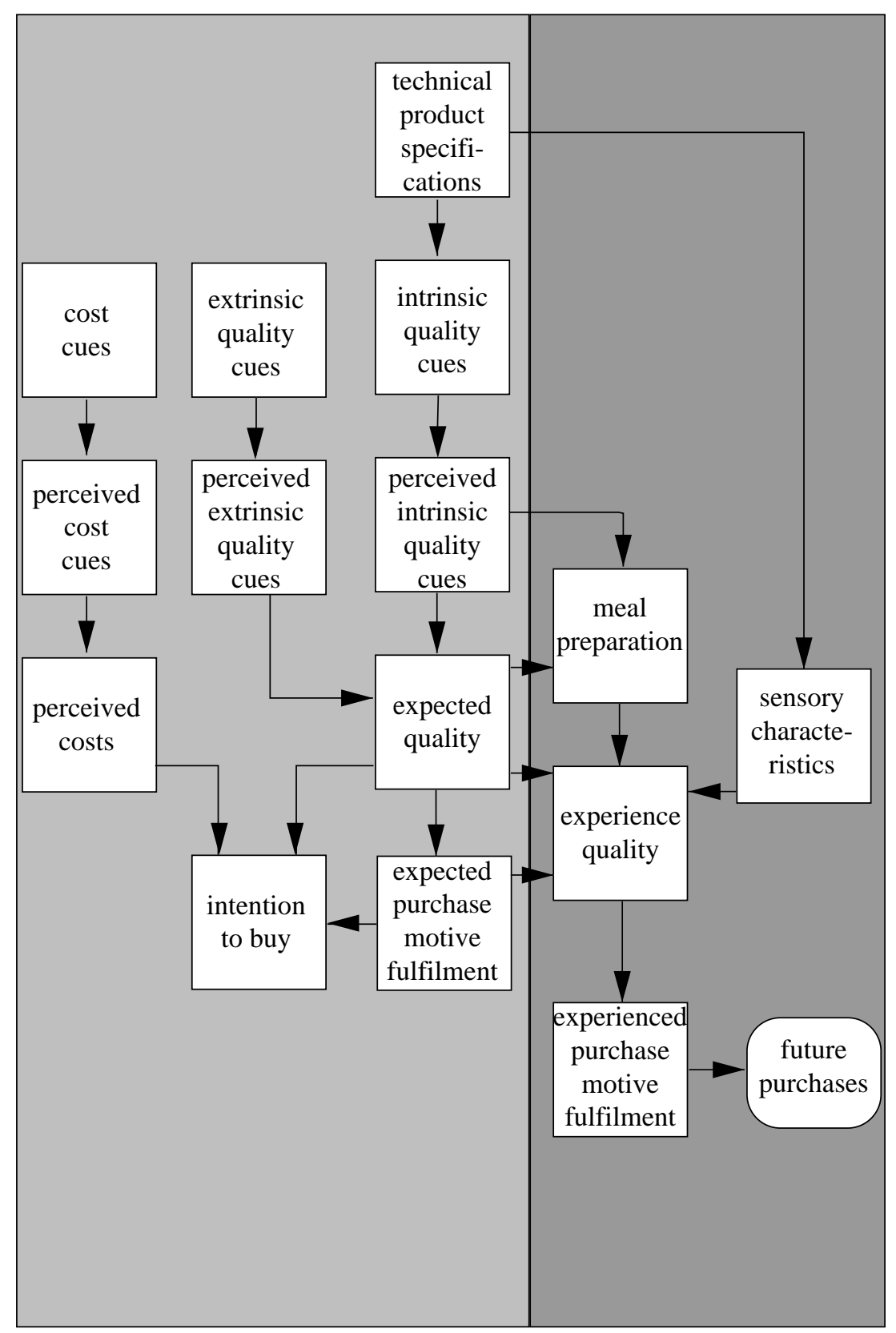

before purchase

after purchase

(from Grunert, Hartvig Larsen, Madsen \& Baadsgaard, 1996)

The only study known to us explicitly employing a hierarchical approach and dealing with the relationship between expected and experienced quality is the one by Steenkamp and van Trijp (1990). They had consumers rate various steak cuts on nine intrinsic quality cues, later reduced to three underlying factors, and related these both to a number of technical product specifications and to an overall judgment of expected quality. Consumers also had the opportunity to taste the meat and rate it on a number of quality aspects, which were related to a gl obal measure of experienced quality. Also these quality aspects were related 
to the technical product specifications. Results showed that the technical product specifications related to expected quality were quite different from those relating to experienced quality, and that the correlation between expected and experienced quality was not very high. This study captures several basic features of the Total Food Quality Model, namely the distinction between expected and experienced quality, the distinction between quality cues and quality aspects, and the relation to technical product specifications.

This paper reports on a cross-cultural study aimed at estimating the whole lefthand section (except technical specifications) of the Total Food Quality Model, ie, the before purchase part of it. This should shed more light on how both intrinsic and extrinsic quality cues and cost cues are perceived and used to infer expected quality and purchase motive fulfilment, and how this affects purchase intention. Substantially, the insights gained should be informative with regard to the devel opment of product and communication strategies in the beef sector. Methodologically, this is the first attempt at a quantitative estimation of the Total Food Quality Model and breaks new ground in the application of hierarchical models to the analysis of quality perception of food. Finally, the use of a crosscultural approach takes into account the fact that food, more than most other consumer products, has considerable cultural significance (Askegaard \& Madsen, 1995; Fischler, 1990; Mennell et al., 1992), emphasising that results from one country may not be readily generalisable to other countries.

The methodology employed is an extended form of conjoint analysis, which will be described in the next section.

\section{EXTENDING CONJ OINT ANALYSIS}

Conjoint analysis was introduced to consumer research in the early seventies (Green \& Rao, 1971; Green \& Srinivasan, 1978), and has been widely applied since then (Cattin \& Wittink, 1982, 1989). In its most basic form, it is concerned with explaining consumer preference for a set of objects by the attributes of these objects, employing an additive model:

(1) $\quad s_{j}=\sum_{p=1}^{t} f_{p}\left(y_{j p}\right)$

with

$\mathrm{S}_{\mathrm{j}}=$ preference for object $\mathrm{j}$

$\mathrm{y}_{\mathrm{jp}}=$ level of pth attribute for object $\mathrm{j}$

$f_{p}=$ function specifying how the attribute levels contribute to overall preference

The function $\mathrm{f}$ can take various forms, eg, the contribution to preference can be linear or according to deviation from an ideal point of $y$, but the most common 
functional form used is the part-worth function, where the contribution to preference for each level of attribute $p$ is estimated separately. Preference is measured by presenting the respondents with a set of stimuli, which are usually constructed by combining the various levels of the various attributes in a factorial design, resulting in orthogonality of the attributes. The part-worth function can then be estimated by either metric (OLS) or non-metric al gorithms; for all practical purposes, there seem to be no major differences in results between the various algorithms (Carmone, Green \& J ain, 1978; Cattin \& Wittink, 1977). If OLS is used, the conjoint analysis model reduces to a simple dummy variable regression:

$$
s_{j}=\sum_{p=1}^{t} \sum_{q=1}^{u} \beta_{q p} d_{q p j}
$$

with

$\beta_{\mathrm{qp}}=$ regression coefficient giving contribution of level $\mathrm{q}$ of attribute $\mathrm{p}$ to preference

$\mathrm{d}_{\mathrm{qpj}}=1$ if object $\mathrm{j}$ has level $\mathrm{q}$ of attribute $\mathrm{p}, 0$ otherwise

Conjoint analysis data can be collected in various ways, the major dimensions of differentiation being whether full profiles are used or not, how the stimuli were designed, how the stimuli are presented, and how preference is measured. Full profiles, ie, descriptions of objects employing all attributes which are part of the study, contrast with the trade-off method, where attributes are presented pairwise. The stimuli can be presented verbally, as pictures, or as real objects. Preference is usually measured either by having the respondents rank the stimuli or by having the respondent rate them on a rating scale.

We can easily extend conjoint analysis to the case where the set of attributes determines not one, but several dependent variables - ie, where we replace unidimensional preference by a more complex set of variables describing consumer preference formation or quality perception. Referring back to the Total Food Quality Model in figure 1, the set of cost cues, extrinsic quality cues and intrinsic quality cues can be regarded as a set of profiles, where each profile can be translated into an $\mathrm{m} \times 1$ vector of dummy variables, $\xi$. All the remaining variables further down the model, ie, perceived cues, expected qual ity, expected purchase motive fulfilment, and intention to buy, can be conceived as forming an $n$ $x 1$ vector of dependent variables, $\eta$. The relationships between the set of cues and the set of dependent variables would be given by an $\mathrm{n} \times \mathrm{m}$ matrix $\Gamma$, and the relationships among the dependent variables by $a \mathrm{n} \times \mathrm{n}$ matrix $\mathrm{B}$. We then obtain the following model:

$$
\eta=B \eta+\Gamma \xi
$$

This is a traditional structural equation model and can be estimated using, eg, LISREL. 
In administering this extended type of conjoint analysis, some modifications with regard to classic conjoint analysis have to be made. The major difference is that the respondent has to respond to each profile not just once, but on several dimensions, corresponding to the set of variables in $\eta$. Depending on how large a subset of the Total Food Quality Model is to be estimated, this can be a considerable burden on the respondent, and will consequently limit the number of profiles a respondent is able to handle.

In classic conjoint analysis, respondents usually rate a set of profiles corresponding to a reduced orthogonal design, which allows the estimatation of the part-worths at the individual level. This puts rather severe limitations on the number of attributes and the number of levels which can be included in the profiles. If the number of profiles a respondent can realistically respond to is further reduced in the extended form of conjoint analysis envisaged here, this would reduce the number of attributes and their levels which can be included still further, at least as long as one wants to retain the possibility of estimating the model parameters at the individual level.

Estimating model parameters at the individual level is important if the aim of the analysis is to segment consumers according to their part-worths, and/or if the aim of the analysis is to predict market shares and how they will vary with variations in attribute levels. However, when the main research interest is in understanding the consumer quality perception process, ie, arriving at estimates of the various relationships in figure 1 , individual level estimates are not strictly necessary. To the extent that a group of respondents can be regarded as homogeneous, ie, as representative specimen of a larger group one wants to describe, this opens up for new ways of administering profiles and solving the problem of limited numbers of attributes. Such a way has been advocated by Rossi (see, eg, Rossi \& Anderson, 1982, and the other contributions in Rossi \& Nock, 1982; see also Grunert, 1985, for a consumer research application) in their factorial survey approach. Devel oped mainly with regard to sociological applications, where the stimuli would be social situations described by a large number of attributes, he proposes that each respondent rates a set of stimuli which are a random sample of a complete factorial design (which he calls a factorial object universe). Samples from a complete factorial design retain the property of orthogonality within the limits of sampling error, and while this error will be large at the level of the individual respondent, it will be small at the aggregate level, if each respondent receives an independent sample from the total factorial object universe. Using this approach, there are no actual limits with regard to the number of attributes which can be included in profiles, and reliable parameter estimates can be obtained in the aggregate even when each respondent rates only a small number of profiles, if the assumption of respondent homogeneity is warranted.

In the next two sections, we describe a study using this modified form of conjoint analysis to estimate the before purchase part of the Total Food Quality Model. 


\section{DESIGN OF STUDY AND DATA COLLECTION}

\section{Design of stimulus material and dependent variables}

This study was carried out in four countries: France, Germany, Spain, and the United Kingdom. In each of the four countries two focus groups with regular users of beef were conducted in order to generate concepts corresponding to the constructs in figure 1. Specifically, it was attempted to generate intrinsic and extrinsic quality cues which consumers use when buying beef, aspects of expected quality, and purchase motives.

\section{Quality cues}

In all countries, the respondents mentioned a long list of quality cues: colour, smell, use-by date, the way the meat is cut, display hygiene, packaging, price, weight, conspicuous bones/veins, deep-frozen or fresh, marbling, fat lumps, fat rims, fat on the whole, the colour of fat, and consistency. Based on these results, and cross-validating with previous studies on the quality perception of beef or meat (see above), the following quality cues with the following levels were selected for the study:

intrinsic quality cues:

- $\quad$ cut: steak, roast, cubed, minced

- $\quad$ colour: light red, medium red, dark red for roast and steak; lighter red and darker red for cubed and minced

- $\quad$ fat lumps: major, minor (for steak, roast, and cubed only)

- $\quad$ fat rim: yes, no (for steak and roast only)

- $\quad$ marbling: high, low (for steak and roast only)

- fat content: high, low (for minced only)

extrinsic quality cues:

- $\quad$ price: low, medium, high

- $\quad$ origin: no information, Denmark, I reland (in the UK: Scotland)

- information on animal production: no information, information this meat is from animals bred and fed with due consideration for animal welfare and without artificial hormones and additives'

The set of intrinsic quality cues formed a complete factorial design with 56 combinations. The Danish Meat Research Institute was asked to produce a set of 56 colour photographs of pieces of meat corresponding to the 56 profiles. Pieces of meat were selected from slaughtering lines to correspond with the desired profiles as closely as possible. To reduce uncontrolled variation in other variables, pieces of meat were photographed as roast, and parts of these same pieces were then sliced, cubed and minced for the other levels of the cut variable.

Price levels were obtained by showing the pictures of roast/steak/cubed/minced to local butchers in the respective country and asking them to estimate the average price of this kind of product. This price was then used as the medium level; high and low levels were obtained by adding and subtracting 15\% from the medium price. 
Most beef is sold without country-of-origin information. However, consumers did mention it as a possible concern. Since I rish beef was the most notable example of origin-branded beef in France, Germany, and Spain, this was used as an example, and Scotland was used in the UK for a similar reason. Denmark was included as a second possible origin.

Animal welfare issues, and concern about additives and artificial hormones in meat have been debated to some extent in recent years, which motivates the inclusion of this extrinsic cue.

All extrinsic information was printed on cards, presented to the respondent along with the photograph of the piece of meat.

A complete factorial design combining all intrinsic and extrinsic cues comprises 1008 product profiles.

One extrinsic cue of some importance, which was not used as part of the profiles, refers to place of purchase. Consumers in all four countries have a choice of places of purchase, with supermarkets and butchers' shops being the main alternatives. Since meat presentation differs considerably in supermarkets and at butchers', it was believed that this variable could not realistically be incorporated into the profiles. Instead, respondents were asked to rate each profile with regard to whether they imagine that this piece of meat would be bought from a butcher's.

\section{Quality aspects}

As regards the higher level aspects of quality, ie, the abstract attributes consumers would like to infer from the quality cues, these turned out to be quite similar across the four countries in the focus groups. The most important ones were:

- taste

- tenderness

- juiciness

- freshness

- leanness

- healthiness

- nutrition

Respondents rated each profile with regard to these seven quality aspects on 7point agree-disagree scales.

\section{Purchase motives}

The qualitative analyses have shown that the following basic motives were the ones most marked in all four countries:

- Tradition and security. Beef can be used to cook traditional dishes, which contributes towards a feeling of security.

- Variation. Beef is versatile; this not only makes it possible to use in many different kinds of dishes and on different occasions, but also to provide variation in everyday life. 
- $\quad$ Atmosphere and social life. Beef is regarded as being suitable for social occasions where people meet.

- $\quad$ Acceptable to children. People buy beef because of the expected satisfaction it will give.

- Acceptable to guests. Beef is regarded as suitable for entertaining.

- Demonstration of cooking abilities. Beef is good for proving both to yourself and others how good a cook you are.

- $\quad$ Status. More than any other kind of meat, beef is regarded as being highly suitable for festive occasions and for impressing people.

Again, respondents rated each profile with regard to these seven purchase motives on 7-point agree-disagree scales.

\section{Selection of respondents and data collection}

The study was designed to shed light on the quality perception process of medium to heavy users of beef. In each country, available market information was used to delimit a group of respondents, using demographic criteria, which would fulfil this criterion. All respondents were women with responsibility for shopping and preparing food in their households; in addition to that, there were quotas for age, children at home, and social class. Based on the screening criteria thus developed, 200 consumers were interviewed in each country. Interviews were made as hall tests in central locations at two or three cities in the respective countries.

Each respondent rated four profiles selected from the total list of 1006 possible profiles. Each profile was rated only by one respondent, corresponding to the philosophy of the factorial survey approach described above. Thus, in each country a total of 800 different profiles were rated by the 200 respondents.

For each profile, the respondent rated perceived colour of the meat (four levels), perceived fat content (three levels), and perceived value for money (three levels). They then rated the seven quality aspects and the seven purchase motives. They rated the perceived purchase outlet and intention to purchase.

After rating the four profiles, respondents answered a number of background questions on frequency of purchase of beef products, demographics etc.

\section{RESULTS}

\section{Dimensionality of quality aspects and purchase motives}

As a first step in data analysis, principal components analyses (with varimax rotation) were conducted for the quality aspects and purchase motives items. As can be seen in table 1, all quality aspect items loaded on one common factor in Germany, Spain, and the UK, whereas all purchase motive items loaded on a second common factor. Combining these items into scales yielded very high Cronbach's alphas. It can therefore be concluded that quality of beef is a onedimensional concept for the consumers in the German, Spanish and UK samples: beef expected to be healthy is al so expected to be tasty, and vice versa. 
Likewise, purchase motives for beef are a one-dimensional concept for these consumers: a piece of meat fulfilling the social motives is also perceived to be able to fulfil the ego-centred motives.

Table 1. Results of exploratory factor analysis of quality aspect and purchase motive items in Germany, Spain and the UK

(factor loadings, highest loadings are in italics, $\mathrm{n}=800$ per country)

\begin{tabular}{|c|c|c|c|c|c|c|}
\hline \multirow[t]{2}{*}{ Item } & \multicolumn{2}{|c|}{ Germany } & \multicolumn{2}{|c|}{ Spain } & \multicolumn{2}{|c|}{ UK } \\
\hline & factor 1 & factor 2 & factor 1 & factor 2 & factor 1 & factor 2 \\
\hline \multicolumn{7}{|l|}{ quality aspects: } \\
\hline healthy & .86 & .22 & .74 & .37 & .76 & .34 \\
\hline fresh & .82 & .24 & .72 & .34 & .77 & .29 \\
\hline lean & .61 & .40 & .46 & .30 & .62 & .40 \\
\hline juicy & .81 & .28 & .81 & .20 & .84 & .28 \\
\hline tasty & .79 & .46 & .83 & .21 & .79 & .40 \\
\hline tender & .75 & .43 & .81 & .21 & .76 & .31 \\
\hline nutritious & .59 & .38 & .73 & .29 & .74 & .46 \\
\hline \multicolumn{7}{|l|}{ purchase motives: } \\
\hline versatile & .19 & .81 & .05 & .65 & .21 & .59 \\
\hline tradition & .18 & .80 & .32 & .55 & .28 & .60 \\
\hline children & .52 & .59 & .32 & .62 & .26 & .62 \\
\hline guests & .46 & .71 & .34 & .68 & .40 & .73 \\
\hline cooking skills & .42 & .73 & .24 & .77 & .29 & .80 \\
\hline status & .56 & .70 & .28 & .77 & .34 & .71 \\
\hline atmosphere & .51 & .70 & .48 & .65 & .52 & .71 \\
\hline $\begin{array}{l}\% \text { of variance ex- } \\
\text { plained by two } \\
\text { factors }\end{array}$ & \multicolumn{2}{|c|}{70.0} & \multicolumn{2}{|c|}{59.1} & \multicolumn{2}{|c|}{64.3} \\
\hline Cronbach's alpha & .92 & .92 & .88 & .86 & .92 & .88 \\
\hline
\end{tabular}

For France, the results are somewhat different. A factor analysis of the quality aspect and purchase motive items combined did not yield a result which was readily interpretable. Separate factor analyses for the quality aspect and the purchase motive items yielded three factors for each group according to the Kaiser criterion. However, an inspection of the scree plot indicated that a two factor solution may be more appropriate for both sets of items. Loadings for the two-factor solutions are seen in table 2 . For quality aspects, healthy, nutritious and juicy go into one factor, and fresh, lean, tasty and tender go into the other. These two factors can be dubbed the reason and the hedonic factors, and the corresponding items, when summed as scales, exhibit satisfactory levels of reliability. As for purchase motives, tradition and versatility load on one factor, and the rest of the items, ie, children, guests, cooking skills, status, and atmosphere, on the other. Reliability analysis indicated that the status and atmosphere items did not fit too well with the others, so it was decided to take these items out of the further analysis for the French sample. Purchase motives were then com- 
bined into two factors: a food culture factor dealing with tradition and versatility, and a social factor dealing with children, guests, and demonstration of cooking skills.

Table 2. Results of exploratory factor analysis of quality aspect and purchase motive items in France

(factor loadings, highest loadings are in italics, $\mathrm{n}=800$ ))

\begin{tabular}{|c|c|c|c|c|}
\hline Item & factor 1 & factor 2 & factor 3 & factor 4 \\
\hline $\begin{array}{l}\text { quality aspects: } \\
\text { healthy } \\
\text { fresh } \\
\text { lean } \\
\text { juicy } \\
\text { tasty } \\
\text { tender } \\
\text { nutritious } \\
\text { purchase motives: } \\
\text { versatile } \\
\text { tradition } \\
\text { children } \\
\text { guests } \\
\text { cooking skills } \\
\text { status } \\
\text { atmosphere }\end{array}$ & $\begin{array}{l}.80 \\
.04 \\
.46 \\
.63 \\
.02 \\
.28 \\
.78\end{array}$ & $\begin{array}{l}.10 \\
.66 \\
.48 \\
.23 \\
.82 \\
.66 \\
.05\end{array}$ & $\begin{array}{l}.01 \\
.19 \\
.81 \\
.69 \\
.77 \\
.18 \\
.36\end{array}$ & $\begin{array}{l}.88 \\
.79 \\
.03 \\
.28 \\
.17 \\
.04 \\
.04\end{array}$ \\
\hline $\begin{array}{l}\% \text { of variance explained } \\
\text { by two factors }\end{array}$ & \multicolumn{2}{|c|}{54.1} & \multicolumn{2}{|c|}{49.0} \\
\hline Cronbach's alpha & .65 & .64 & $.71^{*}$ & .61 \\
\hline
\end{tabular}

*omitting status and atmosphere

The French respondents thus differed from the respondents in the other three countries by having two-dimensional perceptions of both quality aspects and purchase motives.

For further analysis, the quality aspect and purchase motive items were combined into sum scores based on the results just discussed.

\section{Model estimation}

\section{Strategy of analysis}

We now proceed to estimate how the quality cues relate to the variables in the Total Food Quality Model. For each country, we will present estimates for three models. 
In model A, presented in its generic form in figure 2, we assume that perceived fat, perceived colour and perceived costs intervene between the quality cue stimuli and expected quality. We assume that all quality cues, also those not relating to price, fat, and colour, can have a potential effect on perceived fat, perceived colour, and perceived price. We further assume that all quality cue stimuli not relating to fat, price, and colour, also can have a direct effect on expected quality, while the effect of quality cues relating to fat, price and colour on expected quality will be mediated by perceived fat, price, and colour.

In model $B$, presented in its generic form in figure 3 , the perceived quality cue variables, ie, perceived fat, perceived colour and perceived price, are omitted. By comparing models A and B we can see how the addition or omission of these variables affects fit, but the two model variants also supply different types of information. In model $A$, we can see how different cues affect the overall evaluation of price, fat, and colour. But we cannot differentiate how different aspects of fat affect expected quality, because quality is related to the mediator perceived fat, not to the various fat aspects. In model B, we can see how various aspects of fat and colour affect expected quality, but we cannot see how consumers form evaluations of fat or colour or price.

Figure 2. The A model

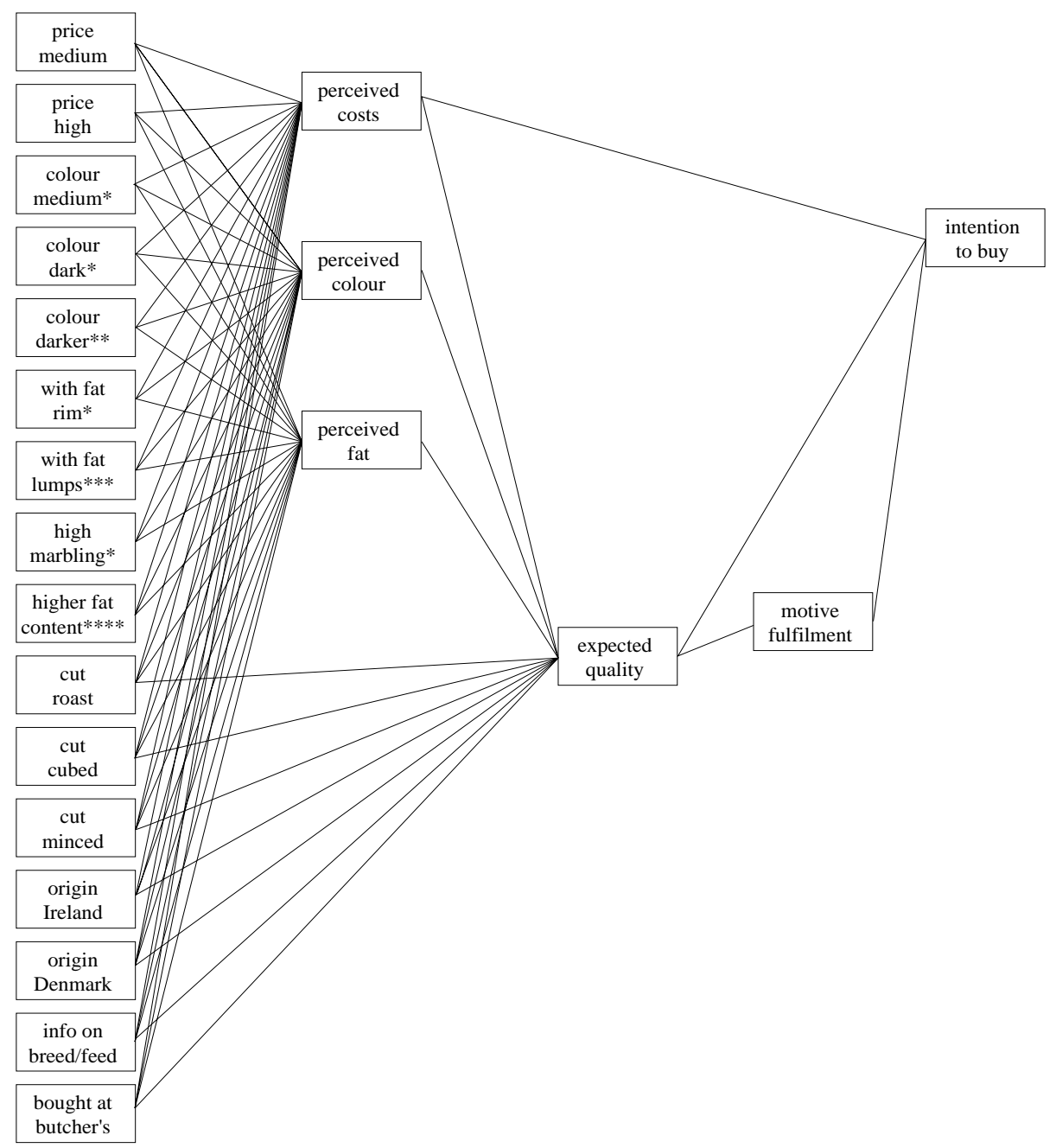

* for steak and roast ** for cubed and minced $* * *$ for steak, roast and cubed $* * * *$ for minced 
Figure 3. The B model

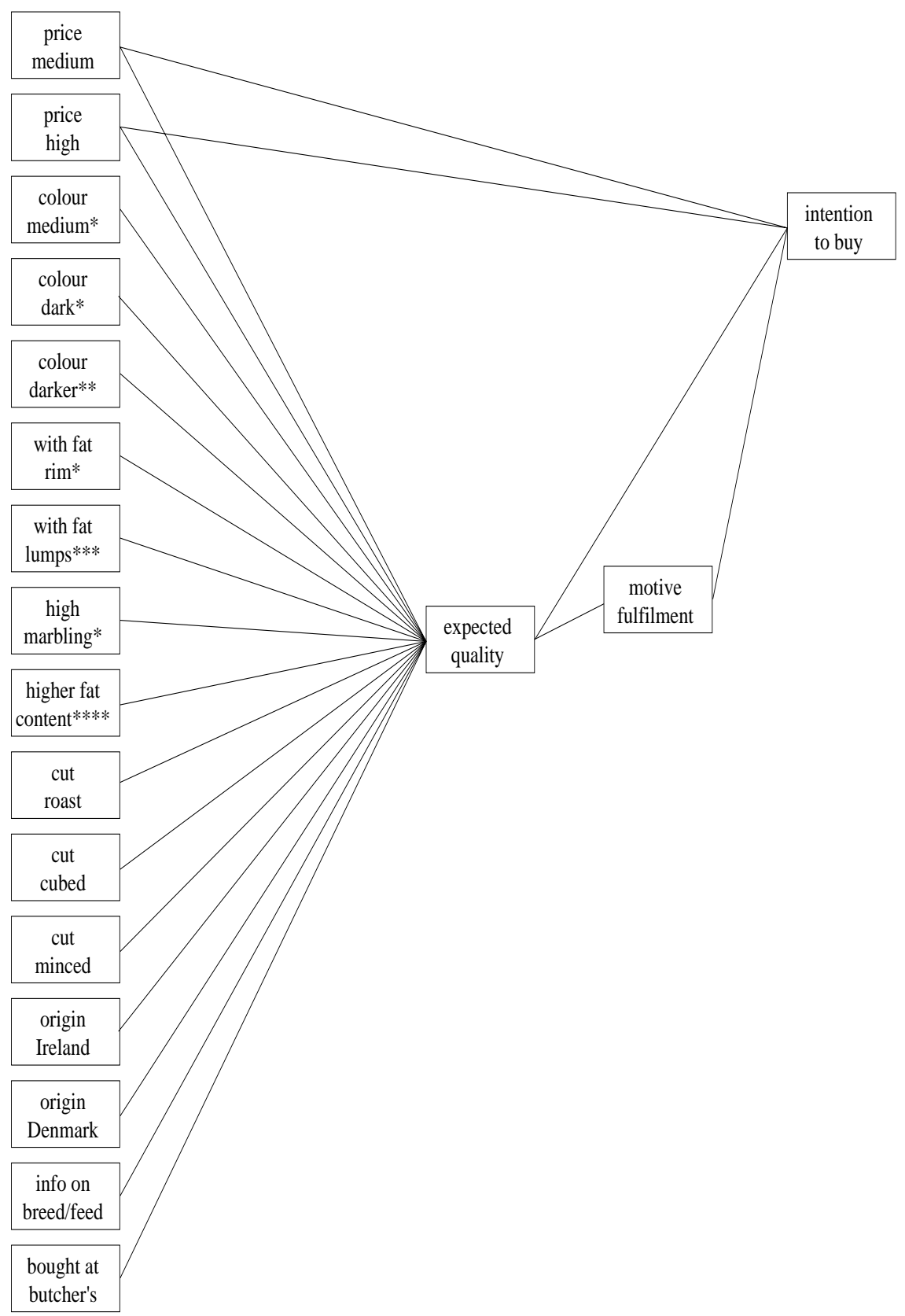

* for steak and roast ** for cubed and minced $* * *$ for steak, roast and cubed $* * * *$ for minced

Model B is a deviation of the Total Food Quality Model in figure 1, since it is assumed in figure 1 that quality cues are mediated by perceived quality cues before influencing perceived quality. Other deviations from the model are possible. It is conceivable that expected purchase motive fulfilment is affected directly by quality cues without being mediated by expected quality. Furthermore, it is possible that consumers infer one perceived quality cue from another. Inspection of modification indices in LISREL can hint as to whether and how fit can be improved by providing for such additional links in the model. For each sample, we have therefore estimated an additional model $C$, which maximises fit within the overall realms of the theoretical framework. This 
means that all relationships which were found to be insignificant in models $A$ and $B$ were taken out of the model, whereas other relationships were added, if they improved fit and if they had a meaningful interpretation. Models A and B therefore follow a confirmatory analysis purpose, whereas model $\mathrm{C}$ has a more exploratory aim which may lead to a refinement of the model in figure 1.

Finally, based on the country results, we investigate whether there is enough similarity in quality perception across countries to estimate a pooled, crosscultural model of the quality perception of beef.

All estimations were done based on covariance matrices. The coefficients were later standardised for ease of interpretation. All dummies are defined relative to a reference level of the corresponding attribute as indicated in figures 2 and 3. Four measures of fit are given for the overall model. The first is the traditional $\chi^{2}$-measure. The second is the root mean square error of approximation (RMSEA), a fit measure taking into account that the model tested may be only approximately correct for the population and therefore is likely to be rejected for larger samples (Browne \& Cudeck, 1993; Steiger, 1990). A RMSEA of below 05 indicates a close fit, and a statistical test for RMSEA $<05$ is available. The two remaining measures of fit are the goodness of fit index (GFI), and the root mean square residual (RMR). For these, no tests are available, but common rules of thumb indicate that a GFI of above .9 and a RMR of below .1 indicate reasonably good fits.

\section{Results for model A}

Table 3 shows the results for model A for Germany, Spain and the United Kingdom; table 4 shows the results for France. Because of the two-dimensional structure assumed for both perceived quality and motive fulfilment in France, the model estimation for France is not in all aspects comparable to those for the other three countries.

As for perceived costs, we find that the three levels of price used in the product profiles led to corresponding increases in perceived costs, indicating validity of the experimental manipulation. It is also clear from the tables, however, that perceived costs are also affected by other variables, notably those relating to fat and cut. In interpreting these effects, it must be kept in mind that these indicate how perceived costs change hol ding everything el se, and notably price, constant. We thus find that, at a given price, the presence of fat lumps in the meat increases the perceived cost in all four countries, ie, the meat is perceived as relatively more expensive than similar meat without fat lumps sold at the same price. Likewise, a higher fat content in minced meat increases perceived costs in all countries except the United Kingdom, and a higher degree of marbling increases perceived costs in Germany and Spain. Presence of a fat rim is the only fat aspect not having an effect on perceived costs in any country. 
Table 3. Results for A model for Germany, Spain, and the United Kingdom (standardised coefficients; those significant at the .05 level are in italics, $n=800$ per country)

\begin{tabular}{|c|c|c|c|c|c|c|}
\hline \multirow{2}{*}{ Relationship } & \multicolumn{2}{|c|}{ Germany } & \multicolumn{2}{|c|}{ Spain } & \multicolumn{2}{|c|}{ United Kingdom } \\
\hline & coefficient & t-value & coefficient & t-value & coefficie & t-value \\
\hline \multicolumn{7}{|l|}{ Perceived costs } \\
\hline price medium & .155 & 4.27 & .141 & 3.84 & .133 & 3.33 \\
\hline price high & .264 & -7.42 & .303 & 8.14 & .191 & 4.68 \\
\hline colour medium* & -.033 & -0.85 & .018 & 0.46 & -.041 & -0.91 \\
\hline colour dark* & -.055 & -1.42 & .014 & 0.35 & -.029 & -0.65 \\
\hline colour darker** & .012 & 0.31 & .098 & 2.38 & -.029 & -0.65 \\
\hline with fat rim* & .064 & 1.83 & .047 & 1.34 & .017 & 0.45 \\
\hline with fat lumps*** & .096 & 2.96 & .110 & 3.32 & .101 & 2.71 \\
\hline high marbling* & .145 & 4.06 & .078 & 2.25 & -.001 & -0.03 \\
\hline higher fat content**** & .092 & 2.22 & .100 & 2.30 & .022 & 0.47 \\
\hline cut roast & -.414 & -11.81 & -.004 & -0.13 & -.143 & -3.64 \\
\hline cut cubed & -.298 & -6.31 & -.360 & -7.60 & -.138 & -2.62 \\
\hline cut minced & -.388 & -6.71 & -.319 & -5.49 & -.175 & -2.68 \\
\hline origin I reland & -.015 & -0.41 & -.059 & -1.64 & -.024 & -0.61 \\
\hline origin Denmark & -.000 & -0.00 & -.083 & -2.35 & .014 & -0.35 \\
\hline info on breed/feed & -.096 & -3.15 & .019 & 0.60 & .002 & 0.05 \\
\hline$r^{2}$ & .26 & & .24 & & .07 & \\
\hline \multicolumn{7}{|l|}{ Perceived colour } \\
\hline price medium & .024 & 0.74 & .016 & 0.45 & .041 & 1.16 \\
\hline price high & .042 & 1.27 & -.019 & -0.54 & .022 & 0.62 \\
\hline colour medium* & .288 & 7.94 & .354 & 9.34 & .240 & 6.06 \\
\hline colour dark* & .456 & 12.76 & .495 & 13.23 & .368 & 9.35 \\
\hline colour darker** & .555 & 15.03 & .418 & 10.73 & .428 & 10.75 \\
\hline with fat rim* & -.065 & -2.12 & -.042 & -1.26 & -.056 & -1.62 \\
\hline with fat lumps*** & -.058 & -1.92 & .011 & 0.33 & -.052 & -1.58 \\
\hline high marbling* & .072 & 2.32 & .018 & 0.54 & .041 & 1.18 \\
\hline higher fat content**** & .002 & 0.06 & -.025 & -0.62 & .107 & -2.60 \\
\hline cut roast & .019 & 1.27 & -.008 & -0.23 & .001 & 0.04 \\
\hline cut cubed & -.039 & -0.92 & -.020 & -0.45 & -.052 & -1.16 \\
\hline cut minced & -.258 & -4.91 & -.167 & -3.06 & -.168 & -2.89 \\
\hline origin I reland & .028 & 0.88 & -.006 & -0.27 & -.016 & -0.46 \\
\hline origin Denmark & .042 & 1.31 & .005 & 0.16 & -.020 & -0.58 \\
\hline info on breed/feed & .038 & 1.35 & .040 & 1.36 & .001 & 0.05 \\
\hline$r^{2}$ & .39 & & .32 & & .27 & \\
\hline \multicolumn{7}{|l|}{ Perceived fat } \\
\hline price medium & -.026 & -0.81 & -.007 & -0.22 & -.033 & -0.93 \\
\hline price high & -.054 & -1.69 & -.021 & -0.64 & -.058 & 1.69 \\
\hline colour medium* & .027 & 0.79 & .022 & 0.64 & .055 & -1.45 \\
\hline colour dark* & -.072 & -2.04 & -.075 & -2.21 & -.037 & -1.00 \\
\hline colour darker** & .044 & 1.26 & .166 & 4.68 & .072 & 1.89 \\
\hline with fat rim* & .345 & 11.20 & .237 & 7.57 & .291 & 8.66 \\
\hline with fat lumps*** & .423 & 14.20 & .447 & 14.96 & .322 & 9.90 \\
\hline high marbling* & .277 & 8.99 & .320 & 10.31 & .309 & 9.13 \\
\hline higher fat content**** & .350 & 9.35 & .430 & 11.34 & .282 & 7.11 \\
\hline cut roast & .080 & 2.55 & -.030 & -0.98 & .095 & 2.86 \\
\hline cut cubed & -.218 & -5.30 & -.218 & -5.27 & -.170 & -3.80 \\
\hline cut minced & -.543 & -10.59 & -.574 & -11.23 & -.401 & -7.14 \\
\hline origin I reland & .029 & 0.91 & .015 & 0.49 & -.014 & -0.40 \\
\hline origin Denmark & -.026 & -0.85 & -.005 & -0.16 & .005 & 0.17 \\
\hline info on breed/feed & .000 & -0.01 & .002 & -0.07 & -.047 & -1.59 \\
\hline$r^{2}$ & .42 & & .42 & & .32 & \\
\hline
\end{tabular}


Table 3. continued

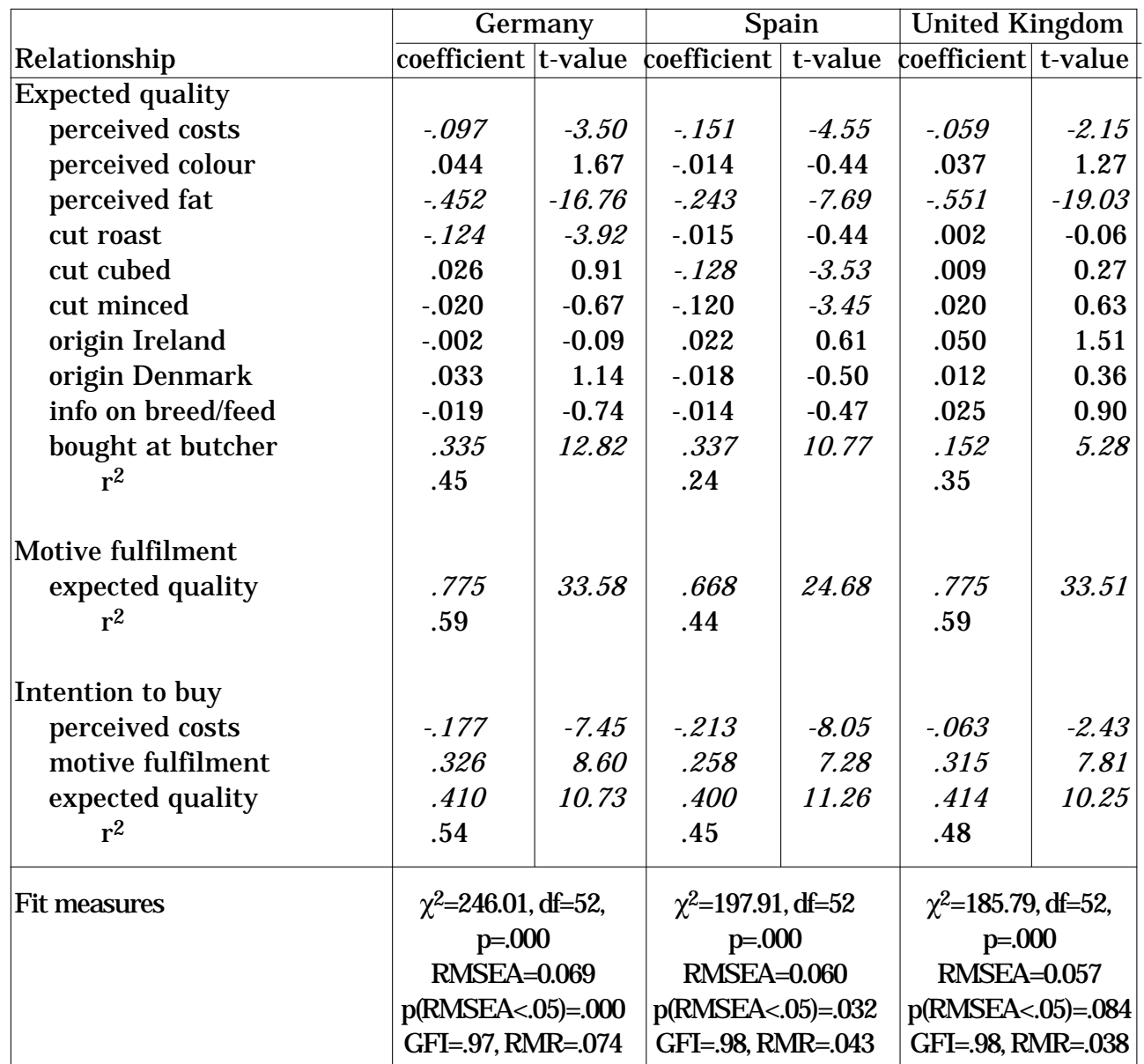

* for steak and roast ** for aubed and minced *** for steak, roast and aubed **** for minced

Several cut variables also influence perceived costs. Cubed meat and minced meat are regarded as less costly (compared to steaks) in Germany, Spain, and the United Kingdom, but cubed meat is regarded as more costly in France. Roast is regarded as considerably less costly in Germany and somewhat less costly in the United Kingdom, but as more costly in France. There are also two weak effects of extrinsic cues on perceived costs: in Spain, imported meat is regarded as less costly if offered at the same price, and in Germany the same is true for meat 'from animals bred and fed with due consideration for animal welfare and without artificial hormones and additives.'

As for perceived colour, the results show that the experimental variations in colour lead to corresponding changes in the perception of colour, validating the experimental manipulation. In addition to that, minced meat is uniformly perceived as lighter in colour in all four countries. A higher fat content in minced meat leads to perceiving a lighter colour in France and the United Kingdom. 
Table 4. Results for A model for France

(standardised coefficients; those significant at the .05 level are in italics, $n=800$ )

\begin{tabular}{|c|c|c|c|c|c|}
\hline Relationship & oefficient & t-value & Relationship & coefficient & t-value \\
\hline Perceived costs & & & Expected quality & & \\
\hline price medium & .135 & 3.67 & 'reason' & & \\
\hline price high & .335 & 8.89 & perceived costs & .008 & 0.22 \\
\hline colour medium* & -.025 & -0.62 & perceived colour & -.099 & -2.72 \\
\hline colour dark* & -.078 & -1.97 & perceived fat & -.115 & -3.22 \\
\hline colour darker** & -.117 & -2.69 & cut roast & -.001 & -0.02 \\
\hline with fat rim* & .045 & 1.24 & cut cubed & -.033 & -0.85 \\
\hline with fat lumps*** & .098 & 2.82 & cut minced & -.068 & -1.65 \\
\hline high marbling* & .043 & 1.18 & origin I reland & -.099 & -2.41 \\
\hline higher fat content***** & .190 & 2.95 & origin Denmark & -.049 & -1.25 \\
\hline cut roast & .276 & 7.54 & info on breed/feed & -.063 & -1.75 \\
\hline cut cubed & .273 & 5.61 & bought at butcher & -.012 & 0.02 \\
\hline cut minced & -.016 & -0.26 & $r^{2}$ & .03 & \\
\hline origin Ireland & -.039 & -1.06 & & & \\
\hline origin Denmark & -.018 & -0.50 & Expected quality & & \\
\hline info on breed/feed & -.022 & -0.67 & 'hedonic' & & \\
\hline$r^{2}$ & .20 & & perceived costs & -.009 & -0.24 \\
\hline & & & perceived colour & -.048 & -1.34 \\
\hline Perceived colour & & & perceived fat & -.038 & -1.11 \\
\hline price medium & .045 & 1.32 & cut roast & -.029 & -0.73 \\
\hline price high & .012 & 0.36 & cut cubed & -.039 & -0.99 \\
\hline colour medium* & .340 & 9.13 & cut minced & .016 & 0.42 \\
\hline colour dark* & .459 & 12.50 & origin I reland & .006 & 0.16 \\
\hline colour darker** & .437 & 11.38 & origin Denmark & -.046 & -1.22 \\
\hline with fat rim* & .012 & 0.39 & info on breed/feed & -.061 & -1.74 \\
\hline with fat lumps*** & .022 & 0.68 & bought at butcher & .228 & 8.21 \\
\hline high marbling* & .018 & 0.55 & $r^{2}$ & .09 & \\
\hline higher fat content***** & $* \quad-.092$ & -2.32 & & & \\
\hline cut roast & .014 & 0.45 & Motive fulfilment & & \\
\hline cut cubed & -.029 & -0.67 & 'culture' & & \\
\hline cut minced & -.250 & -4.61 & quality 'reason' & .154 & 4.72 \\
\hline origin Ireland & .002 & -0.10 & quality 'hedonic' & .332 & 10.24 \\
\hline origin Denmark & -.045 & -1.91 & $r^{2}$ & .14 & \\
\hline info on breed/feed & .019 & 0.64 & & & \\
\hline$r^{2}$ & .35 & & $\begin{array}{l}\text { Motive ful filment } \\
\text { 'social' }\end{array}$ & & \\
\hline Perceived fat & & & quality 'reason' & .249 & 7.59 \\
\hline price medium & .012 & 0.36 & quality 'hedonic' & .272 & 8.58 \\
\hline price high & .000 & 0.00 & $r^{2}$ & .14 & \\
\hline colour medium* & .042 & 1.12 & & & \\
\hline colour dark* & -.101 & -2.70 & Intention to buy & & \\
\hline colour darker** & .104 & 2.67 & perceived costs & -.167 & -5.14 \\
\hline with fat rim* & .268 & 8.10 & motive 'culture' & .155 & 4.32 \\
\hline with fat lumps*** & .338 & 10.52 & motive 'social' & .080 & 2.20 \\
\hline high marbling* & .251 & 8.30 & quality 'reason' & .105 & 3.11 \\
\hline higher fat content***** & .344 & 8.50 & quality 'hedonic' & .180 & 5.06 \\
\hline cut roast & .081 & 2.50 & $r^{2}$ & .15 & \\
\hline cut cubed & -.216 & -4.87 & & & \\
\hline cut minced & -.432 & -7.78 & Fit measures & $\chi^{2}=450.96, \mathrm{df}$ & $=52$ \\
\hline origin Ireland & .001 & 0.03 & & $p=000$ & \\
\hline origin Denmark & .006 & 0.18 & & RMSEA $=0.0$ & \\
\hline info on breed/feed & -.029 & -0.99 & & $p($ RMSE $A<0$ & $5)=.00$ \\
\hline$r^{2}$ & .32 & & & $\mathrm{GFI}=96, \mathrm{RM}$ & $\mathrm{R}=070$ \\
\hline
\end{tabular}


All aspects of fat varied in the stimulus material - presence of fat lumps and fat rims, degree of marbling, fat content of minced meat - affected the respondents' perception of fat. The effects are of about equal size, with fat lumps slightly more important for fat perception than the other factors. Cubed and especially minced meat is uniformly perceived as containing less fat in all four countries - it must be kept in mind that this meat was cut from the same pieces as those shown as steak and roast, so that objectively the fat content was the same. Roast is perceived as containing more fat than steak (also there the meat was actually the same) in France and the United Kingdom. Also, in France, Germany and Spain meat with a dark colour is perceived as containing less fat than meat with a medium or light colour.

The two factors affecting expected quality in Germany, Spain, and the United Kingdom are perceived fat and whether the meat was bought from a butcher's or from a supermarket. The coefficient for perceived costs is also significant, but has no reasonable causal interpretation: perceived costs were included as potential determinants of expected quality, based on the reasoning that price may be used as an indicator of quality. The results clearly show, however, that the perceived costs variable was interpreted by the respondents as a measure of relative value, so that a possible causal relationship between expected quality and perceived costs should go in the other direction. We will return to this when discussing model $\mathrm{C}$.

In France, none of the variables in the study seem to explain expected quality very well. The 'reason' dimension of quality is related to perceived fat, lighter meat seems to be preferred, and imported meat seems to be refused, but the effects are quite modest and the amount of explained variance is extremely low. As for the 'hedonic' dimension, buying from the butcher's is the only variable having an effect.

Expected motive fulfilment is strongly related to expected quality, as anticipated. Also, expected quality affects intention to buy both directly and indirectly via expected motive fulfilment in all four countries. Perceived costs have, as expected, a negative influence on intention to buy in all four countries.

For Germany, Spain, and the United Kingdom in most equations $30-40 \%$ of variance are explained, and the overall fit of the models, while obviously leaving room for improvement, is not disastrous. The same cannot be said for the French data, with very low percentages of explained variance and a poor fit of the overall model.

\section{Results for model B}

The results in table 5 support the importance of fat and buying from a butcher's for expected quality. However, a slight differentiation of the fat aspects is possible. While all four fat aspects contribute with roughly equal weight to perceived fat as shown in table 3 , table 5 shows that the presence of a fat rim actually does not affect expected quality in Spain, and has also slightly lower effect on expected quality than the other fat variables in Germany and the United Kingdom. Also we can detect two weak colour effects in table 5, which did not appear in table 3. In Germany, dark red colour leads to higher expected 
Table 6. Results for B model for France

(standardised coefficients; those significant at the .05 level are in italics, $n=800$ )

\begin{tabular}{|c|c|c|c|c|c|c|}
\hline Relationship & coefficient & t-value & \multirow{2}{*}{$\begin{array}{l}\text { Relationship } \\
\text { Expected quality } \\
\text { 'hedonic' }\end{array}$} & \multicolumn{2}{|c|}{ coefficient } & t-value \\
\hline \multicolumn{3}{|l|}{$\begin{array}{l}\text { Expected quality } \\
\text { 'reason' }\end{array}$} & & & & \\
\hline price medium & .005 & 0.13 & price medium & & .058 & 1.40 \\
\hline price high & .049 & 1.22 & price high & & .062 & 1.56 \\
\hline colour medium* & -.009 & -0.21 & colour medium* & & -.001 & -0.02 \\
\hline colour dark* & -.035 & -0.82 & colour dark* & & -.011 & -0.26 \\
\hline colour darker** & -.100 & -2.12 & colour darker** & & -.034 & -0.78 \\
\hline with fat rim* & -.070 & -1.73 & with fat rim* & & -.036 & -0.95 \\
\hline with fat lumps*** & -.052 & -1.36 & with fat lumps ${ }^{* * *}$ & & -.041 & -1.14 \\
\hline high marbling* & -.036 & -0.93 & high marbling* & & -.003 & -0.08 \\
\hline higher fat content**** & k* $\quad-.082$ & -1.67 & higher fat content' & $t * * * *$ & -.023 & -0.49 \\
\hline cut roast & -.010 & -0.26 & cut roast & & -.032 & -0.85 \\
\hline cut cubed & .038 & 0.69 & cut cubed & & -.006 & -0.12 \\
\hline cut minced & .084 & 1.31 & cut minced & & .086 & 1.37 \\
\hline origin I reland & -.099 & -2.46 & origin Ireland & & .006 & 0.15 \\
\hline origin Denmark & -.046 & -1.14 & origin Denmark & & -.050 & -1.23 \\
\hline info on breed/feed & -.064 & -1.75 & info on breed/feed & & -.061 & -1.81 \\
\hline bought at butcher & -.008 & -0.22 & bought at butcher & & .288 & 8.23 \\
\hline$r^{2}$ & .03 & & $r^{2}$ & & .10 & \\
\hline \multirow{2}{*}{\multicolumn{3}{|c|}{$\begin{array}{l}\text { Motive fulfilment } \\
\text { 'culture' }\end{array}$}} & \multicolumn{4}{|l|}{ Intention to buy } \\
\hline & & & price medium & & .032 & 0.84 \\
\hline quality 'reason' & .155 & 4.72 & price high & & .017 & 0.45 \\
\hline quality 'hedonic' & .334 & 10.25 & motive 'culture' & & .147 & 3.99 \\
\hline \multirow[t]{2}{*}{$r^{2}$} & \multirow{2}{*}{\multicolumn{2}{|c|}{.14}} & motive 'social' & & .073 & 2.07 \\
\hline & & & quality 'reason' & & .105 & 3.11 \\
\hline \multirow{2}{*}{\multicolumn{3}{|c|}{$\begin{array}{l}\text { Motive fulfilment } \\
\text { 'social' }\end{array}$}} & \multirow{3}{*}{$\begin{array}{l}\text { quality 'hedonic' } \\
r^{2}\end{array}$} & & .186 & 5.17 \\
\hline & & & & & .12 & \\
\hline \multirow{2}{*}{$\begin{array}{l}\text { quality 'reason' } \\
\text { quality 'hedonic' }\end{array}$} & \multirow{2}{*}{$\begin{array}{l}.248 \\
.272\end{array}$} & \multirow{2}{*}{$\begin{array}{l}7.58 \\
8.58\end{array}$} & & & & \\
\hline & & & \multirow{2}{*}{\multicolumn{4}{|c|}{$\begin{array}{l}\chi^{2}=305.88, d f=48, \\
p=000 \\
\text { RMSEA }=0.083 \\
p(R M S E A<05)=.00 \\
G F I=97, R M R=.066\end{array}$}} \\
\hline$r^{2}$ & \multicolumn{2}{|l|}{.14} & & & & \\
\hline
\end{tabular}

\section{Results for model C}

As noted, model $\mathrm{C}$ was developed from model $\mathrm{A}$ by taking all non-significant variables out and adding new relationships as long as they improve fit and have a meaningful interpretation. As shown in table 7, and to a lesser degree in table 8 for the French data, the resulting models indeed have quite good fit measures. 
Table 7. Results for $\mathrm{C}$ model for Germany, Spain, and the United Kingdom (standardised coefficients; all relationships significant at the .05 level, $n=800$ for each country)

\begin{tabular}{|c|c|c|c|c|c|c|}
\hline \multirow{2}{*}{ Relationship } & \multicolumn{2}{|c|}{ Germany } & \multicolumn{2}{|c|}{ Spain } & \multicolumn{2}{|c|}{ United Kingdom } \\
\hline & coefficient & t-value & coefficient & t-value & coefficien & t-value \\
\hline \multicolumn{7}{|l|}{ Perceived costs } \\
\hline price medium & .161 & 4.52 & .148 & 4.12 & .146 & 3.73 \\
\hline price high & .277 & 7.91 & .325 & 8.93 & .210 & 5.26 \\
\hline cut roast & -.454 & -13.09 & --- & --- & -.166 & -4.16 \\
\hline cut cubed & -.247 & -7.33 & -.329 & -10.38 & -.101 & -2.69 \\
\hline cut minced & -.273 & -8.24 & -.195 & -6.25 & -.104 & -2.73 \\
\hline info on breed/feed & -.082 & -2.63 & -- & -- & -- & -- \\
\hline perceived fat & --- & --- & .176 & 5.29 & .130 & 3.14 \\
\hline expected quality & -.353 & -7.67 & -.175 & -5.32 & -.100 & -2.41 \\
\hline$r^{2}$ & .27 & & .28 & & .10 & \\
\hline \multicolumn{7}{|l|}{ Perceived colour } \\
\hline colour medium & .312 & 9.50 & .365 & 10.72 & .276 & 7.71 \\
\hline colour dark* & .477 & 14.45 & .509 & 14.99 & .395 & 10.90 \\
\hline colour darker** & .527 & 15.77 & .403 & 11.77 & .401 & 11.44 \\
\hline high marbling* & .092 & 2.94 & --- & --- & .105 & 3.00 \\
\hline cut minced & -.278 & -8.34 & -.182 & -5.41 & -.233 & -6.57 \\
\hline perceived fat & --- & --- & --- & --- & -.136 & -4.42 \\
\hline$r^{2}$ & .38 & & .32 & & .28 & \\
\hline \multicolumn{7}{|l|}{ Perceived fat } \\
\hline colour dark* & -.066 & -2.49 & -.092 & -3.17 & --- & --- \\
\hline colour darker** & --- & --- & .201 & 4.57 & --- & --- \\
\hline with fat rim* & .320 & .326 & .230 & 7.53 & .272 & 8.19 \\
\hline with fat lumps*** & .385 & 13.23 & .427 & 14.48 & .322 & 10.13 \\
\hline high marbling* & .265 & 8.85 & .307 & 10.04 & .315 & 9.43 \\
\hline higher fat content***** & .320 & 8.91 & .412 & 11.04 & .284 & 6.97 \\
\hline cut roast & .080 & 2.65 & --- & --- & .095 & 2.88 \\
\hline cut cubed & -.196 & -5.99 & -.224 & -6.05 & -.130 & -3.55 \\
\hline cut minced & -.479 & -11.52 & -.569 & -12.14 & -.355 & -7.43 \\
\hline bought at butcher & -.175 & -6.29 & -.102 & -3.71 & --- & --- \\
\hline$r^{2}$ & .44 & & .43 & & .30 & \\
\hline \multicolumn{7}{|l|}{ Expected quality } \\
\hline perceived colour & .056 & 2.23 & -- & -- & --- & --- \\
\hline perceived fat & -.616 & -11.88 & -.243 & -7.54 & -.709 & -13.66 \\
\hline high marbling* & -.094 & -3.08 & -.107 & -3.10 & --- & --- \\
\hline cut roast & -.060 & -2.26 & --- & --- & --- & --- \\
\hline cut cubed & --- & --- & -.097 & -2.98 & --- & --- \\
\hline cut minced & -- & -- & -.117 & -3.58 & -- & -- \\
\hline bought at butcher & .302 & 9.91 & .337 & 11.01 & .164 & 5.88 \\
\hline$r^{2}$ & .46 & & .25 & & .34 & \\
\hline
\end{tabular}


minced is no indicator of quality (actually a negative one in Spain), it could possibly lead to the fulfilment of purchase motives in a way not connected to quality aspects. Results from the focus groups suggest the interpretation that minced meat is a very versatile ingredient giving many possibilities to please the family, which are not mediated by the quality aspects like tenderness, healthiness or taste of the meat. The positive effect of minced meat on purchase intention in the United Kingdom may have a similar interpretation. We also find for both Germany and Spain that perceived fat decreases expected motive fulfilment, an effect beyond the one mediated by expected quality, and a direct effect of perceived fat on intention to buy in the United Kingdom. These direct effects of product attributes on intention to buy can possibly be interpreted as indicators of a higher degree of habitualisation and/or lower involvement of the UK respondents. Finally, in the U nited Kingdom there is also a colour effect on intention to buy. The effect is the opposite of the German one: darker meat tends to increase likelihood of buying via expected quality in Germany, whereas it decreases intention to buy in the United Kingdom.

Table 8. Results for $\mathrm{C}$ model for France

(standardised coefficients; all relationships significant at the .05 level, $n=800$ )

\begin{tabular}{|c|c|c|c|c|c|}
\hline \multirow{2}{*}{\begin{tabular}{|l|} 
Relationship \\
Perceived costs \\
\end{tabular}} & \multicolumn{2}{|c|}{ coefficient t-value } & Relationship & \multicolumn{2}{|c|}{ coefficient t-value } \\
\hline & & & \multicolumn{3}{|c|}{ Expected quality 'hedonic' } \\
\hline & .135 & 3.67 & bought at butcher & .288 & 8.94 \\
\hline price high & .342 & 9.09 & $r^{2}$ & .08 & \\
\hline colour darker** & -.138 & -3.20 & & & \\
\hline cut roast & .262 & 7.13 & Motive fulfilment & & \\
\hline cut cubed & .340 & 8.19 & 'culture' & & \\
\hline cut minced & .154 & 3.65 & quality 'reason' & .153 & 4.41 \\
\hline perceived fat & .163 & 4.99 & quality 'hedonic' & .330 & 9.60 \\
\hline$r^{2}$ & .19 & & $r^{2}$ & .17 & \\
\hline Perceived colour & & & Motive fulfilment & & \\
\hline colour medium* & .345 & 10.19 & 'social' & & \\
\hline colour dark* & .469 & 14.01 & quality 'reason' & .249 & 7.09 \\
\hline colour darker** & .418 & 12.29 & quality 'hedonic' & .272 & 8.04 \\
\hline higher fat content**** & $k \quad-.092$ & -2.32 & $r^{2}$ & .18 & \\
\hline cut minced & -.231 & -5.27 & & & \\
\hline$r^{2}$ & .34 & & Intention to buy & & \\
\hline & & & perceived costs & -.108 & -3.76 \\
\hline Perceived fat & & & motive 'culture' & .140 & 4.48 \\
\hline colour dark* & -.123 & -3.92 & motive 'social' & .073 & 2.32 \\
\hline colour darker** & .104 & 2.64 & quality 'reason' & .077 & 2.51 \\
\hline with fat rim* & .268 & 8.09 & quality 'hedonic' & .141 & 4.14 \\
\hline with fat lumps*** & .331 & 10.34 & perceived fat & -.421 & -14.51 \\
\hline high marbling* & .268 & 8.15 & bought at butcher & .113 & 3.70 \\
\hline higher fat content**** & .344 & 8.50 & $r^{2}$ & .35 & \\
\hline cut cubed & -.265 & -6.70 & & & \\
\hline cut minced & -.477 & -9.30 & Fit measures & $\chi^{2}=128.25, d$ & 103, \\
\hline$r^{2}$ & .32 & & & $p=047$ & \\
\hline & & & & RMSEA $=0.0$ & \\
\hline Expected quality & & & & $\mathrm{p}(\mathrm{RMSEA}<$ & )=1.0 \\
\hline 'reason' & & & & $\mathrm{GFI}=99, \mathrm{RN}$ & $=.021$ \\
\hline perceived colour & -.061 & -1.87 & & & \\
\hline perceived fat & -.093 & -2.85 & & & \\
\hline origin Ireland & -.085 & -2.56 & & & \\
\hline$r^{2}$ & .02 & & & & \\
\hline
\end{tabular}




\section{The cross-cultural core model}

For Germany, Spain and the United Kingdom, the results of the estimation of model $C$ do show quite a bit of congruence. For these three countries, we have therefore also estimated a model taking into account all those relations which appeared for all three countries in the $\mathrm{C}$ models. We may regard the resulting model as the cross-cultural core of the quality perception of beef for these three countries. It is not a complete description of the quality perception process, but it shows those elements of it which the respondents in these three countries seem to have in common. The model is shown in figure 4.

Figure 4. The cross-cultural model (common core of quality perception in Germany, Spain, the United Kingdom, pooled estimates, standardised coefficients, all coefficients significant at the .05 level)

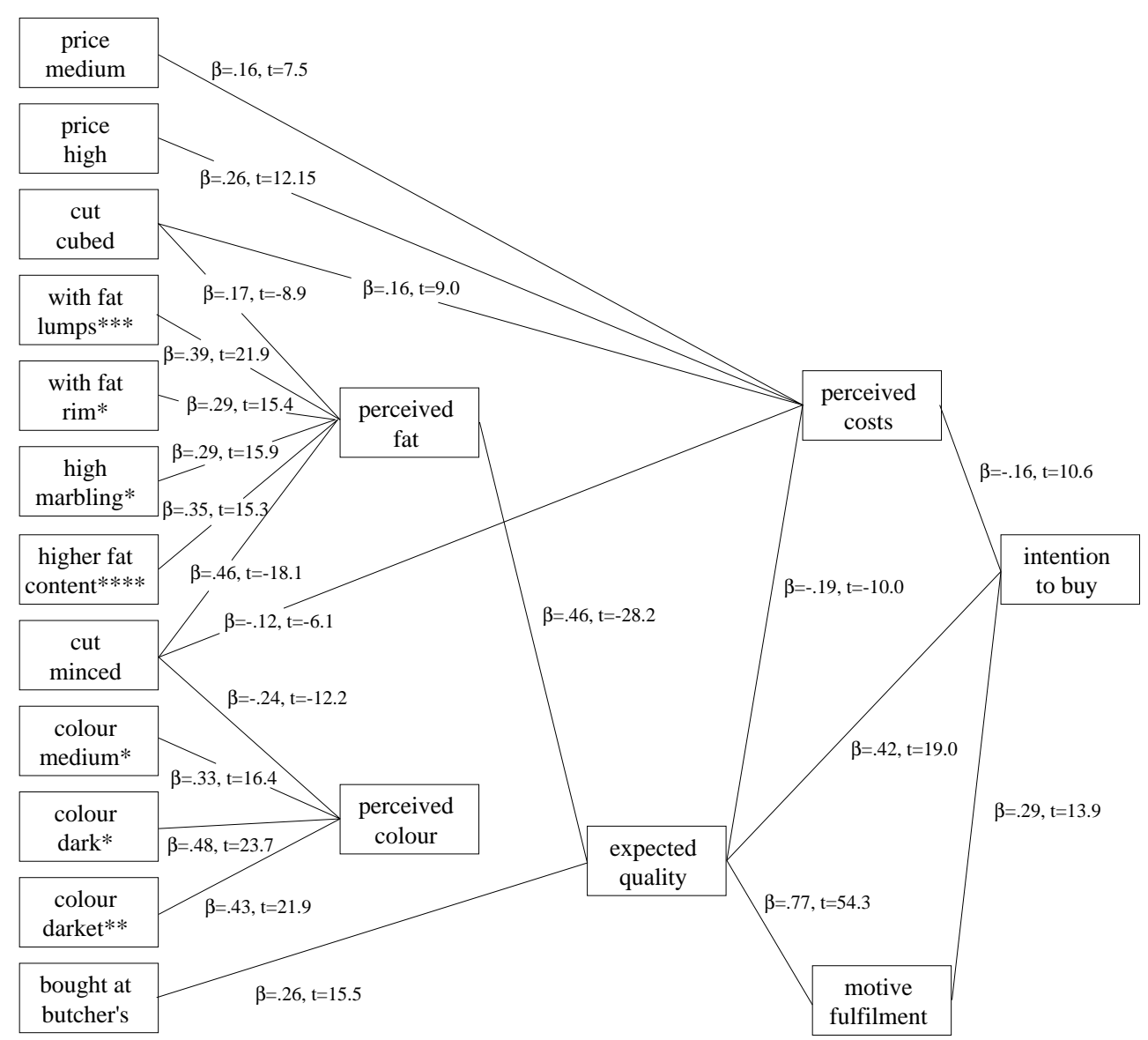

* for steak and roast ** for cubed and minced $* * *$ for steak, roast and cubed $* * * *$ for minced Fit measures: $\chi^{2}=1148.04, \mathrm{df}=252, \mathrm{p}=.000, \mathrm{RMSEA}=0.039, \mathrm{p}(\mathrm{RMSEA}<.05)=1.00, \mathrm{GFI}=.95, \mathrm{RMR}=.12$ 
We see the main elements discussed above: perceived costs as a compromise of give and get variables, ie, price, cut, and expected quality. Perceived fat as being influenced by all fat aspects and by the mincing of the meat. Perceived fat, together with buying at a butcher's, as the main determinants of expected quality. We also see that, while the perception of colour is quite stable across the three groups of respondents, there is no cross-culturally uniform effect of perceived colour on quality perception. This was not to be expected, given that it was shown that darker col our has positive effects in Germany, whereas lighter colour has positive effects in Spain and the United Kingdom.

\section{Discussion AND CONCLUSIONS}

In the present study, we have used an extended form of conjoint analysis in order to investigate the quality perception process taking place before or during the purchase of beef. The study was based on groups of respondents in four European countries. The results of the study have implications in three areas. There are methodological implications for the usefulness of extended forms of conjoint analysis for the study of quality perception processes. There are theoretical implications for the model employed, the Total Food Quality Model. And there are substantial implications for the marketing of beef.

As for the methodological implications, we have used a form of conjoint analysis which deviates from the more traditional forms applied in consumer research in two ways. Firstly, and most importantly, we have employed not one, but an array of dependent measures on which product profiles were to be rated, resulting in covariance matrices, with the product profile as the unit of analysis, which allow estimating not only how quality cues affect the quality perception process, but also how the various elements of the quality perception process are related to each other. Secondly, we have overcome the limitations given by a comparatively large number of quality cues and a large number of dependent variables by employing the factorial survey approach, where each respondent receives an idiosyncratic sample of product profiles. It should also be noted that we have applied this in a cross-cultural setting.

Mostly the results have been encouraging in the sense that the resulting data led to results with meaningful interpretations and, with the exception of the French data, reasonable amounts of explained variance and good measures of fit. Also, the fact that the results achieved in three out of the four countries studied are quite comparable adds to their face validity. At the same time, however, the fact that the French data showed very different patterns and that the French quality perception process was in general much more difficult to explain than the quality perception process in the other three countries emphasises the importance of cultural differences in studying the quality perception of food.

The results have a number of theoretical implications for the Total Food Quality Model.

Firstly, the construct perceived costs needs further theoretical scrutiny. It is common in consumer behaviour models employing a hierarchical approach to explain purchases by a balancing of give and get components (Zeithaml, 1988). 
The present study suggests that these components are not in fact independent, ie, that consumers do not form a perception of the give components independently of the get components. The perceived costs construct, as it turned out in this study, is a subjective measure of relative value, which weights prices with some of the benefits expected from the product.

Secondly, the study shows many examples of cross-references among quality cues, eg, cut and colour cues being used to infer fat content. While this phenomenon was recognised a long time ago (eg, Cox, 1967), it is not usually explicitly integrated into models of food quality perception.

Thirdly, the results have shown that expected quality is not the only mediator between quality cues and expected fulfilment of purchase motives and intention to buy, as stipulated in the Total Food Quality Model. Of course, one might argue that this is due to the fact that important quality aspects may have been missing from the operationalisation of expected quality used in the present study, and that the direct links found between quality cues and purchase fulfilment/intention to buy would disappear had they been included. Still, it is conceivable that a quality cue is seen as contributing to a purchase motive without contributing to a quality aspect, like when minced meat was hypothesised to contribute to versatility in cooking without affecting one of the quality aspects.

Related to this, and fourthly, direct relationships between quality cues and intention to buy may also be explained by low involvement and/or high degrees of habitualisation. In a low involvement situation, consumers may never form explicit quality expectations, but may have come to associate certain product attributes with their daily purchases and use these to ensure a one-dimensional, non-specific satisfaction with the purchase after consumption, without engaging in the formation of expected quality. Even with higher degrees of involvement, high degrees of habitualisation may lead to similar phenomena: due to frequent repetitive behaviour direct associations have been formed in consumer memory between quality cues and purchase intention, and the originally underlying knowledge structures mediating these by quality expectations and expected purchase motive fulfilment may become less accessible, leading to considerable measurement error and randomness when trying to ascertain them.

A number of substantial implications can be derived for the marketing of beef.

Two factors appeared to dominate the formation of expected quality: perceived fat and the place of purchase. Together, these show considerable uncertainty of consumers with regard to the formation of quality expectations. Fat content is actually not a good predictor of the quality aspects consumers are interested in, and to the extent it is, the prediction goes the other way round than consumers suppose. Especially a certain degree of marbling is actually a factor that contributes to tenderness, taste and juiciness, whereas consumers seem to think it detracts from it. Thus, the formation of expectations about taste, tenderness and juiciness mainly based on fat attributes is actually dysfunctional. The high importance attached to buying from a butcher's shows that consumers would like to entrust the purchase decision in the hands of an expert, who would be more capable than themselves in predicting the outcome of the meal. The use of colour as a cue in the quality perception process does not add to the accuracy of the prediction of quality aspects either. 
Given this obvious uncertainty on the part of consumers, it is also interesting to note that the other extrinsic cues tested in the study, country of origin and information about breeding and feeding, had practically no effect on the formation of quality expectations at all. This poses a dilemma to the marketer of superior beef. If a producer is able to produce beef which actually is superior in terms of the quality aspects consumers are interested in - taste, tenderness, juiciness etc. - how can this message be conveyed to the consumer if the consumer is not able to recognise this superior quality, and at the same time tends to ignore auxiliary cues that were meant to suggest superior quality (as in the case of Irish beef)? One option is to cooperate with specialised retailing outlets, building on the consumer tendency to trust the retail expert. But with the declining market share of butchers' this may not be a feasible solution. Perhaps the other extrinsic cues currently used have not to a sufficient extent made clear to the consumer what they stand for, and done this in a way trustworthy to the consumer. A combination of branding and quality grading, firmly related to actual superiority in terms of those quality aspects consumers are interested in, and promoted in a close co-operation between retailer and manufacturer in a way which establishes trustworthiness of the claims made, could possibly both help consumers in forming quality expectations with higher validity and manufacturers to communicate product superiority. 


\section{REFERENCES}

Andersen, E. S. (1994). Theevolution of credencegoods: A transaction approach to product specification and quality control. MAPP working paper no. 21. Aarhus: The Aarhus School of Business.

Askegaard, S. \& Madsen, T. K. (1995). European food cultures: An exploratory analysis of food related preferences and behaviour in European regi ons. MAPP working paper no. 26. Aarhus: The Aarhus School of Business.

Barton, R. A. (1970). Consumer preferences and the classification and grading of beef carcasses. In A. G. Campbell (Ed.), New Zeal and beef, pp. 423-443. N ew Zeal and I nstitute of Agricultural Science.

Browne, M. W. \& Cudeck, R. (1993). Alternative ways of assessing model fit. In K. A. Bollen \& J. S. Long (Eds.), Testing structural equation models. London: Sage.

Carmone, F. J ., Green, P. E. \& J ain, A. K. (1978). Robustness of conjoint analysis: Some Monte Carlo results. J ournal of Marketing Research, 15, 300-303.

Cattin, P. \& Wittink, D. R. (1977). Further beyond conjoint measurement: toward a comparison of methods. In: W. D. Perreault (Ed.), Advances in consumer research, 4, pp. 41-45. Atlanta, GE: Association for Consumer Research.

Cattin, P. \& Wittink, D. R. (1982). Commercial use of conjoint analysis: A survey. J ournal of Marketing, 46(3), 44-53.

Cattin, P. \& Wittink, D. R. (1989). Commercial use of conjoint analysis: An update. J ournal of Marketing, 53(3), 91-96.

Cox, D. F. (1967). The sorting rule model of the consumer product evaluation process. In D. F. Cox (Ed.), Risk taking and information handling in consumer behaviour, pp. 324369. Boston: Graduate School of Business Administration, Harvard University.

Darby, M. R. \& Karni, E. (1973). Free competition and the optimal amount of fraud. The J ournal of Law and Economics, 16, 67-88.

Dransfield, E. et. al. (1984). Beef quality assessed at European research centres. Meat Science, 10, 1-20.

Fischler, J.-C. (1990). L'omnivore Paris: Odile J acob.

Fishbein, M. \& Ajzen, I. (1975). Belief, attitude, intention and behavior. Reading, MA: Addison-Wesley.

Geistfeld, L. V. Sproles, G. B. \& Badenhop, S. B. (1977). The concept and measurement of a hierarchy of product characteristics. In W. D. Perreault (Eds.), Advances in consumer research, vol . 4, pp. 302-307. Atlanta, GE : Association for Consumer Research.

Godt, J., K ristensen, K., Poulsen, C. S., J uhl, H. J \& Bech, A. C. (1996). Verbraucherstudie zum Thema dänische männliche, nicht kastrierte Schweine. Fleischwirtschaft, 75(5) 383385.

Green, P. E. \& Rao, V. R. (1971). Conjoint measurement for quantifying judgmental data. J ournal of Marketing Research, 8, 355-363.

Green, P. E. \& Srinivasan, V. (1978). Conjoint analysis in consumer research: I ssues and outlook. J ournal of Consumer Research, 5, 103-123.

Grunert, K. G. (1985). Methoden zur Messung der Bedeutung von Produktmerkmalen: Ein Vergleich. J ahrbuch der Absatz- und Verbrauchsforschung, 31, 167-187. 
Grunert, K. G. (1986). Cognitive determinants of attribute information usage. J ournal of Economic Psychol ogy, 7, 95-124.

Grunert, K. G. (1989). Another attitude on multi attribute attitude theories. In K. G. Grunert \& F. Ölander (Eds.), Understanding economic behaviour, pp. 213-230. Dordrecht: Kluwer.

Grunert, K. G., Hartvig Larsen, H., Madsen, T. K. \& Baadsgaard, A. (1996). Market orientation in food and agriculture. Boston, MA: Kluwer.

Gutman, J. (1982). A means-end chain model based on consumer categorization processes. J ournal of Marketing, 46(2), 60-72.

Gutman, J. (1991). Exploring the nature of linkages between consequences and values. J ournal of Business Research, 22(2), 143-149.

Maguire, K. (1994). Perceptions of meat and food: Some implications for health promotion strategies. British Food J ournal, 96(2), 11-17.

Mennell, S., Murcott, A. \& van Otterloo, A. (1992). The sociology of food, eating, diet and culture. London: Sage.

Nelson, P. (1970). I nformation and consumer behavior. J ournal of Political Economy, 78, 311-329.

Nelson, P. (1974). Advertising as information. J ournal of Political Economy, 82, 729-754.

Olson, J. C. (1989). Theoretical foundations of means-end chains. Werbeforschung \& Praxis, (5), 174-178.

Olson, J . C. \& J acoby, J . (1972 ). Cue utilization in the quality perception process. In M. Venkatesan (Ed.), Proceedings of the Third Annual Conference of the Association for Consumer Research, pp. 167-179. Chicago: Association for Consumer Research.

Olson, J. C. \& Reynolds, T. J. (1983). Understanding consumers' cognitive structures: Implications for advertising strategy. In L. Percy \& A. G. Woodside (Eds.), Advertising and consumer psychology, pp. 77-90. Lexington, MA: Lexington Books.

Oude Ophuis, P. A. M. (1994). Sensory evaluation of 'free range' and regular pork meat under different conditions of experience and awareness. Food Quality and Preference, 5, 173-178.

Richardson, N. J., Shepherd, R. \& Elliman, N. A. (1993). Current attitudes and future influences on meat consumption in the UK. Appetite, 21, 41-51.

Rossi, P. H. \& Anderson, A. B. (1982). The factorial survey approach: An introduction. In P. H. Rossi \& S. L. Nock (Eds.), Measuring social judgments, pp. 15-67. Beverly Hills, CA: Sage.

Rossi, P. H. \& Nock, S. L. (1982). Measuring social judgments. Beverly Hills, CA: Sage.

Sapp, S. G. (1991). Impact of nutritional knowledge within an expanded rational expectations model of beef consumption. J ournal of Nutritional Education, 23, 214-222.

Shepherd, R. \& Stockley, L. (1985). Fat consumption and attitudes towards food with a high fat content. Human Nutrition: Applied Nutrition, 39A, 431-442.

Shepherd, R. \& Towler, G. (1992). Nutrition knowledge, attitudes and fat intake: application of the theory of reasoned action. J ournal of Human Nutrition and Dietetics, 5, 387-397.

Steenkamp, J .-B. E. M. (1989). Product quality: An investigation into the concept and how it is perceived by consumers. Assen: Gorcum. 
Steenkamp, J.-B. E. M. \& van Trijp, H. C. M. (1989). Quality guidance: A consumer-based approach for product quality performance. In G. J . Avlonitis (Ed.), Marketing thought and practice in the 1990's: Proceedings of the 18th annual meeting of the European Marketing Academy, vol. II, pp. 1191-1217. Athens: EMAC.

Steiger, J. H. (1990). Structural model evaluation and modification: An interval estimation approach. Multivariate Behavi oural Research, 25, 173-180.

Wilde, L. L. (1980). The economics of consumer information acquisition. J ournal of Business, 53, 143-158.

Woodward, J . (1988). Consumer attitudes towards meat and meat products. British Food J ournal, 90(3), 101-104.

Zeithaml, V. A. (1988). Consumer perceptions of price, quality, and value: A means-end model and synthesis of evidence. J ournal of Marketing, 52(3), 2-22. 